\title{
NOTAS SOBRE LA OBRA CIENTÍFICA DE COSERIU (14)
}

\author{
JosÉ POLO \\ Universidad Autónoma de Madrid \\ jose.polo@uam.es \\ II \\ ARQUITECTURA DE LA LENGUA \\ 3: pistas bibliográficas en lecturas de Coseriu ( 5)
}

0

Las presentes notas han sido redactadas bajo el proyecto La obra científica de Eugenio Coseriu: ordenación, estudio y edición (Ministerio de Ciencia y Tecnología, BFF200201827).

\section{Período 1956-1960}

1. En la entrega actual no he manejado separatas, etc., de Coseriu (que no sé si, para los materiales de ahora, existen en su archivo), sino que, a partir de someras indicaciones suyas en hojas, más o menos volanderas, he completado las respectivas fichas bibliográficas y posteriormente he ido, aquí y allá, fotocopiando esos artículos. Esto quiere decir que, no contando con las señales lectoras del maestro, al leer con atención todos los estudios que mencionaré, he procurado aislar los pasajes que pudieran haber llevado a Coseriu a asociarlos, en mayor o menor grado, con el espacio conceptual de los ejes diastrático y diafásico, los cuales, como sabemos, no pueden degajarse con cortes limpios de las otras dos coordenadas de su tetralogía: los ejes diatópico y diacrónico.

2. Anuncio, igualmente, que con el texto de ahora doy por concluidas las que podemos considerar muy complejas secciones preliminares de esta serie. Así, pues, en la siguiente entrega quedaremos ya instalados en la parte nuclear de la investigación, con el espacio de los ejes diastrático y diafásico en plena efervescencia: antecedentes en Coseriu, estudiosos que se han servido, en este punto, de su doctrina o que han discrepado en cuanto a la necesidad de hacer entrar en juego la cuarta perspectiva (la del eje diafásico), así como el hecho del olvido del origen, no meramente «terminológico» (Saussure, Flydal, Coseriu...), de las denominaciones de esos campos y de otros muy relacionados, convirtiendo en un bien «mestenco» realidades que, afortunadamente, aún conservan rasgos de su identidad genealógica (siempre, claro está, con las ventanas abiertas a los descubrimientos con que la historia de nuestra ciencia, en cualquier momento, puede sorprendernos). 
A

1. ABERCROMBIE, David, «English Accents», en English Language Teaching, VII/1952-1953, págs. 113-123; recogido como capítulo IV, págs. 41-56, en su libro Problems and Principles in Language Study, Longman, Londres, 1956, ${ }^{2} 1963$ (he utilizado la reimpresión de 1973). No voy a citar fragmento alguno porque ya lo he hecho, con este y otro estudio del autor y en forma amplia (peripecias de su búsqueda bibliográfica, etc.), en Eugenio COSERIU, «La estructura del saber lingüístico» (dentro de la serie «Eugenio Coseriu y su entorno. Textos originales y traducciones de una época prodigiosa: Montevideo, 1951-1963»: ordenados y dispuestos para la imprenta por José Polo), en Analecta Malacitana, XXIII-2/2000, págs. 437-452 (para lo relativo a Abercrombie, con la cita de varios textos, págs. 445-446.

2. FoURQUET, Jean, «Linguistique structurale et dialectologie», que he fotocopiado de Fragen und Forschungen im Bereich und Umkreis der Germanischen Philologie. Festgabe für Theodor Frings zum 70. Geburstag (23.Juli 1956), Deutsche Akademie der Wissenschaften zu Berlin (Veröffentlichungen des Instituts für Deutsche Sprache und Literatur), Akademie-Verlag (herausgegeben von Elisabeth Karg-Gasterstädt und Johannes Erben), Berlín, 1956, págs. 190-203. Puede entenderse como preparación del terreno para lo diastrático-diafásico. Consta de los siguientes epígrafes: parte introductoria sin título, págs. 190-192; 1, «Étude descriptive d’un dialecte» (págs. 192-196); 2, «Géographie linguistique» (págs. 196-200); 3, «Linguistique historique» (págs. 200-203). No voy a citar segmento textual alguno (pues no los veo directamente relacionados con nuestro centro de interés, pero sí mencionaré las páginas en las que aparece algún concepto (Bühnendeutsch, etc.; compárese, de nuestro Amado ALONSO, «El ideal artístico de la lengua y la dicción en el teatro», 1936, 1943 y, finalmente, en Materia y forma en poesía, Gredos, Madrid, 1955, ${ }^{3} 1965$, con reimpresiones varias, págs. 51-77), algún concepto, decía, que nos recuerda lo esencial de nuestro enfoque o nos asocia a ello. Son estas las páginas aludidas: 193 y 200203 (o sea, para esto último, el mencionado epígrafe tercero, «Linguistique historique»). Por lo demás, se trata de un estudio, entiendo, bien fundado y con equilibrio metodológico.

3. UlvestaD, Bjarne, «Approach to Describing Usage of Language Variants», págs. 37-59 en un volumen, sin título genérico, con solo dos trabajos (el primero: Harold E. DRIVER, «An Integration of Functional, Evolutionary, and Historical Theory by Means of Correlations»): «Supplement to International Journal of American Linguistics (vol. 22, núm. 1, enero de 1956), Indiana University Publications in Anthropology and Linguistics («Memoir 12 of the International Journal of American Linguistics»), Waverly Press/Indiana University («under the auspices of Linguistic Society of America, American Anthropological Association with the cooperation of Joint Committee on American Native Languages»); aparecen tres breves párrafos de C. F. Voegelin como «Preface to Two Papers». Estudio concienzudo muy rico, además, en la ilustración de los fenómenos objeto de atención. No es nuclearmente cercano a los ejes diastrático y diafásico, pero no deja de haber segmentos textuales que, al menos, nos los recuerdan: págs. 38, 43 (registros oral y 
escrito novelístico) y 48/nota 31 (de nuevo, observación sobre lo narrativo literario, los factores de estilo, etc.).

4. StAnKiEwicz, Edward, «The Phonemic Patterns of the Polish Dialects. A Study in Structural Dialectology», en For Roman Jakobson. Essays on the Occasion of His Sixtieh Birthday (compiled by Morris Halle, Horace G. Lunt, Hugh McLean y Cornelis H. van Schooneveld), Mouton, La Haya, 1956, págs. 518-530. Estudio sólido y también «leve» en lo diastrático-diafásico y muy bien ilustrado. No obstante, cabe señalar algunos pasajes no tan alejados de nuestro centro de interés: págs. 519 (§1), 522 (§3.3), 523 (§4.1), 528 (§7.1) y $529-530$ (§7.2).

5. PICKFORD, Glenna Ruth, «American Linguistic Geography: a Sociological Appraisal», en Word, 12-2/1956, págs. 211-233 (muy amplia bibliografía: págs. 229-233) . Ya el propio título nos indica mayor proximidad que los trabajos antes fichados a nuestro eje diastrático, aunque se halle en una órbita sociocultural distinta de la de Coseriu; el peso se muestra en lo relativo a los presupuestos sociológicos, etc., de una cartografía lingüística bien orientada. Vale la pena mencionar los diversos epígrafes: tras unos párrafos introductorios sin título y sin estructura numérica (págs. 211-212), vienen (respeto la numeración en romanos): I, «Improving Research Procedure» (212-219); II, «Extending the Scope of Inquiry» (220-229), que es el espacio más cercano a nuestro eje diastrático, particularmente los subepígrafes «Group Affiliations of the Individual» (págs. 220-221), «Conflicts and Cross-Affiliations» (págs. 221-222), «The Factor of Social Class» (pág. 222), «Table of Informants by Types» (págs. 222-224), «Urbanized Society of America» (págs. 224-227) y «Cultural Hierarchy of American Society» (págs. 227-229).

6. Alvar, Manuel, «Diferencias en el habla de Puebla de Don Fadrique (Granada)», en Revista de Filología Española, XL/1956 , págs. 1-32; reimpreso como opúsculo dentro de Publicaciones del Atlas Lingüístico de Andalucía, tomo I, número 3, Granada, 1957, 34 págs. (esta segunda impresión es la que, al parecer, leyó Coseriu). Al final del estudio, la última nota comienza así (modernizo la acentuación): «Este trabajo fue entregado a la imprenta en diciembre de 1953. Dificultades técnicas [abundante transcripción fonética] impidieron su composición[...]». Trabajo ya clásico: se estudian los rasgos lingüísticos diferenciadores del habla de hombres y mujeres. Ello caería, en principio, según mi entender, en un virtual espacio común de los ejes diastrático y diafásico, salvo que se cree una perspectiva individualizada para este tipo de «oposiciones»/contrastes, como, al parecer, queda sugerido en Ambrosio RABANALES cuando, en «Origen y evolución de mis modelos lingüísticos (en Actas del primer simposio bienal de académicos de lingüística y filología [13-14 de diciembre de 1979], Instituto de Letras, Universidad Católica de Chile, Santiago, 1981, págs. 28-74), tras referirse (pág. 72) a las normas culta e inculta como los dos extremos de un continuo y al «punto de vista fásico» («norma formal y norma informal», extremos, igualmente, de un continuo), señala (pág. 73): «Consecuente conmigo mismo, procuro señalar también diferencias diagénitas[hombres/mujeres] y diaérgicas[por motivos de profesión, de trabajo], en los casos en que me ha sido posible». Antes (en Orbis, 
I/1952, págs. 19-24) había publicado Gregorio SALVADOR «Fonética masculina y fonética femenina en el habla de Vertientes y Tarifa (Granada», trabajo, en última impresión, recogido en su libro Estudios dialectológicos (Paraninfo, Madrid, 1987, págs. 182-189). Interesa ver la «Apostilla de 1977» (págs. 187-188), pues en ella se explica, entre otras cosas, el origen de ese breve estudio (Sever Pop, creación de la revista Orbis, etc.): «Mi maestro, Manuel Alvar, que conocía mi hallazgo porque me dirigía la tesis doctoral y estas aldeas eran parte del municipio estudiado, me alentó a enviar la noticia a la revista que se iniciaba. Así cuajó mi trabajillo y, naturalmente, tuve que volver a referirme a ello, con más precisiones acerca del método y los informantes, en el cuerpo de la tesis[...]» (pág. 187). No está de más recordar, por otra parte, que, en la gigantesca obra del nunca suficientemente ponderado estudioso del lenguaje Manuel Alvar, es muy extensa e intensa la atención (casi podríamos decir que la máxima posible) a los fenómenos encuadrables en nuestros ejes diastrático y diafásico (véase, por ejemplo, un mero atisbo, en esta misma serie, en la entrega número 7: ELUA, 13/1999, §1, págs. 299-305); pero ahora se trata únicamente de señalar el hecho de que Coseriu - presumiblemente, hacia 1957- había mencionado el consabido estudio como de interés para lo relativo a los niveles de lengua y estilos del hablar/del habla (los archiconocidos ejes diastrático y diafásico coserianos). Aunque el estudio del Dr. Alvar posee interés en conjunto para nuestro centro de interés, señalaré las páginas (en la impresión de 1957; dos menos en la de 1956) más explícitas o cercanas metodológicamente: 4-5, algo en la 6 y en la 16 y, en general, los apartados 21, «Conclusiones» (págs. 30-33), y 22, «Consideraciones de tipo general» (págs. 33-34).

\section{B}

7. Stankiewicz, Edward, «On Discretenes and Continuity in Structural Dialectology», en Word, 13-1/1957, págs. 44-59. Buen trabajo, como el anterior de este mismo autor (atrás ficha 4). Lo más cercano —o, si se prefiere, lo más fácilmente asociable - a nuestro objeto de estudio se encuentra en los epígrafes números 2 (págs. 4647), 7 (págs. 54-57) y 8 (págs. 57-59).

8. Spence, N. C. W., «A Hardy Perennial: the Problem of La Langue and La Parole», en Archivum Linguisticum, IX-1/1957, págs. 1-27. Estudio muy conocido de Coseriu (lo cita en varios de sus trabajos); además, es autor que ha prestado mucha atención a la obra coseriana (véase, por ejemplo, muestra mínima de antaño, la última nota del artículo en págs. 26-27). Cabe citar como páginas con segmentos textuales que rozan nuestro espacio conceptual, o casi se adentran en él, las siguientes: 3, 6-9 y 11-15.

9. Kurath, Hans, « The Binary Interpretation of English Vowels. A Critique», en Language, 33-2/1957, págs. 111-122. Como los demás trabajos mencionados en la presente entrega, un buen estudio. A efectos de relación con nuestra zona, cabría mencionar, dentro de §7, la observación número 3 (pág. 121).

10. Murat, V. P., Ob osnovnych problemach stilistiki [el profesor Coseriu me lo tradujo, en su momento, como 'Acerca de los problemas fundamentales de la estilística'], 
Editorial de la Universidad de Moscú, 1957. Coseriu remitía a «pág. 7 y sigs. (sobre todo, pág. 21)»; en la primera se menciona a Humboldt: remito, dentro de esta serie, a la entrega número 10: ELUA, 16/2002, págs. 361-366, particularmente a §2, «Wilhelm von Humboldt», págs. 365-366; en la mencionada pág. 7 aparece la referencia al hecho de los estilos de lengua que dependen del asunto del cual se habla y de las personas que hablan y escuchan, etc. Nos hallamos, pues, frente a un trabajo poco conocido que Coseriu, buen conocedor de la lengua rusa (entre otras), supo tener en cuenta y sobre el cual llamó la atención incluso en letra de molde (no me detengo en las varias referencias).

\section{C}

11. Cochrane, G. R., «The Australian English Vowels as a Diasystem», en Word, 15/1959, págs. 69-88. De nuevo, un estudio perfectamente ilustrado y serio en sus planteamientos. Pueden asociarse, en mayor o menor grado, a nuestro centro de interés, ejes diastrático y diafásico, segmentos textuales de los epígrafes 1.1 (pág. 70), 1.3 (pág. 71) y 3.4 («Concluding Remarks», pág. 88).

12. LeOPOLD, Werner F., «The Decline of German Dialects», en Word, 15/1959, págs. 130-153. Una vez más, se trata de un estudio sólido y muy bien documentado. Por otra parte, es, de entre todos los que en la presente entrega han sido fichados, el más cercano al espacio de los ejes diastrático y diafásico. De citar, habría que hacerlo con abundantes pasajes. Me limitaré, pues, a mostrar los diferentes epígrafes, lo que dará una idea precisa acerca de la afirmación, en cuanto proximidad conceptual, que acabo de hacer. Son estas las anunciadas secciones del trabajo: 1.1, «Dialects and Standard» ([pág.] 130); 1.2, «Postwar Migration» (130-131); 1.3, «East German Dialects» (131-132); 1.4, «West German Dialects» (132-133); 2.1, Strengthening of Standard» (133-134); 2.2, «Provincial Colloquial Standards» (134-135); 2.3, "City and Country» (135-136); 2.4, «Variations within the Standard» (136); 2.5, «Meeting of Eastern and Western Standards» (137); 2.6, «Process of Compromise» (137-138); 2.7, «Levels of Colloquial Standard» (138-139); 3.1, «Dialect Survival» (139-140); 3.2, «Conflicts between Adults and Children» (140-141); 3.3, «Adolescents» (141); 4.1, «Collection of Source Materials» (141-142); 4.2, «Example: Swabian in Württemberg» (143-144); 4.3, «Example: Sudeten German Dialect» (145-148); 4.4, «Example: South and North» (148-150); 5.1, «Summary: Method of Presentation» (150-151); 5.2, «Summary: Effect of Migrations Dialects» (151); 5.3, «Summary: Leveling of Colloquial and Dialects» (151-152); 6, «Outlook» (152-153); «Informants Cited» (153).

(continuará) 